\title{
KAJIAN BIOLOGI PERIKANAN IKAN KERAPU BARA DI PERAIRAN KABUPATEN KEPULAUAN RAJA AMPAT
}

\author{
Dwi Ernaningsih ${ }^{1)}$ \\ ${ }^{1)}$ Fakultas Perikanan dan Ilmu Kelautan, Universitas Satya Negara Indonesia
}

\begin{abstract}
Grouper (Epinephelus retouti) or also known as the Red-tipped grouper is one of the economically important type of grouper that is widely exported and live on coral reef ecosystems. Coral reef ecosystem impact damage to biota existence the symbiotes in it, including the grouper bara. Changes the State of the environment influence on the biological condition of the fishery. Research on the study of the fisheries biology grouper done in the waters of Raja Ampat Islands conducted in August 2015. This research aims to analyze the value of (1) the leght at first maturity (Lm), and legth at first capture (Lc); (2) analyze the relationship of length weight (the pattern of growth). The data were analyzed by using the formula: $L_{50}=\frac{-b_{0}}{b_{1}}$ (prediction of the leght at first maturity $=\mathrm{Lm}$ ) and the $\mathrm{L}_{50 \%}=\frac{\mathrm{S} 1}{\mathrm{~S} 2}$ (the legth at first capture $=\mathrm{Lc}$ ); $\mathrm{W}=\alpha \mathrm{L}^{\beta}$ (pattern of growth). The results showed that Grouper Bara in the waters ofWest Waigeo had Lm 29,91 cm dan Lc 25,37 cm, showed that the grouper can't catch $(\mathrm{Lc}<\mathrm{Lm})$. Result of the relationship of length weight, can b value was 2,219 or $\mathrm{b}<3$ (negative allometric, length accretion faster weight accretion). Pattern of growth was allow equation $\mathrm{W}=0,145 \mathrm{~L}^{2,219}$
\end{abstract}

Key words: fisheries biology, Red-tipped grouper, Raja Ampat

\begin{abstract}
ABSTRAK
Ikan kerapu bara (Epinephelus retouti) atau disebut juga Red-tipped grouper merupakan salah satu jenis ikan kerapu ekonomis penting yang banyak diekspor dan hidup pada ekosistem terumbu karang. Kerusakan ekosistem terumbu karang berdampak kepada keberadaan biota yang bersimbiosis di dalamnya, diantaranya adalah ikan kerapu bara. Perubahan keadaan lingkungan berpengaruh terhadap kondisi biologi perikanan. Penelitian tentang kajian biologi perikanan ikan kerapu bara di perairan Kabupaten Raja Ampat dilakukan pada bulan Agustus 2015. Penelitian ini bertujuan untuk (1) menganalisis nilai panjang pertama kali matang gonad (Lm), dan pertama kali tertangkap (Lc); (2) menganalisis hubungan panjang berat (pola pertumbuhan).Data dianalisis dengan menggunakan rumus: $L_{50}=\frac{-b_{0}}{b_{1}}$ (prediksi panjang pertama kali matang gonad $=\mathrm{Lm}$ ) dan $\mathrm{L}$ $50 \%=\frac{S 1}{S 2}$ (panjang pertama kali ditangkap $=\mathrm{Lc}$ ); $\mathrm{W}=\alpha \mathrm{L}^{\beta} \quad$ (pola pertumbuhan). Hasil penelitian menunjukkan bahwa Ikan Kerapu Bara di perairan Waigeo Barat memiliki nilai Lm 29,91 $\mathrm{cm}$ dan Lc 25,37 cm, menunjukkan bahwa ikan yang tertangkap belum layak tangkap (Lc < Lm). Berdasarkan hasil perhitungan hubungan panjang berat, diperoleh nilai b sebesar 2,219 atau nilai $b<3$ yang dengan kata lain pertumbuhan panjang ikan kerapu bara yang tertangkap di Waigeo Barat bersifat allometrik negatif (pertambahan panjang ikan lebih cepat dari pada pertambahan beratnya). Pola pertumbuhan ikan kerapu bara mengikuti persamaan $\mathrm{W}=0,145 \mathrm{~L}^{2,219}$.
\end{abstract}

Kata kunci: biologi perikanan, ikan kerapu bara, Raja Ampat 


\section{PENDAHULUAN}

\section{Latar Belakang}

Ikan kerapu merupakan salah satu ikan laut ekonomis penting yang sekarang ini banyak dibudidayakan dan merupakan komoditas ekspor.Ikan kerapu memiliki 15 genera yang terdiri atas 159 spesis.Satu diantaranya adalah Cromileoptes altivelis yang selain sebagai ikan konsumsi juga juvenilnya juga sebagai ikan hias. Ikan kerapu termasuk famili Serranidae, Subfamili Epinephelinea, yang umumnya di kenal dengan nama groupers, rockcods, hinds, dan seabasses. Ikan kerapu ditemukan diperairan pantai Indo-Pasifik sebanyak 110 spesies dan diperairan Filipina dan Indonesia sebanyak 46 spesies yang tercakup ke dalam 7 genera Aethaloperca, Anyperodon, Cephalopholis, Cromileptes, Epinephelus, Plectropomus, dan Variola (Marsambuana dan Utojo, 2001).

Ikan kerapu bara (Epinephelus retouti)atau disebut juga Red-tipped groupermerupakan salah satu jenis ikan kerapu ekonomis penting yang banyak ditawarkan di restoran mewah, isi ikannya amat lembut dan lezat dijadikan hidangan. Ikan ini hidup di kawasan terumbu karang berkongsi dengan ikan kerapu, banyak terdapat di perairan Asia Tenggara.

Ilmu Biologi Perikanan merupakan salah satu ilmu yang mendasari ilmu-ilmu perikanan tangkap lainnya,metode penangkapan ikan, serta ilmu lainnya.Kajian biologi ikan meliputi sebaran ikan berdasarkan kedalaman perairan (pelagic, mid water dan demersal), anatomi dan fisiologi ikan.Diantaranya adalah hubungan panjang dan berat merupakan aspek biologi perikanan yang perlu di pelajari, kaitannya dengan pola pertumbuhan, nilai panjang pertama kali matang gonad (Lm), dan pertama kali tertangkap (Lc), serta komposisi ukuran.

Kabupaten Kepulauan Raja Ampat memiliki karakter kepulauan yang sangat beragam meliputi atoll pulau-pulau karst, pulau terumbu, taka (path reef), hingga gunung laut (seamount). Ekosistemnya sangat beragam, mulai hutan hujan tropis sampai padang savana di daratan, hingga ekosistem mangrove, dan terumbu karang di pesisir. Keanekaragaman hayati laut tropis yang dimiliki Kabupaten Raja Ampat diperkirakan yang terkaya di dunia pada saat ini, maka tak heran jika para ilmuan menyebutkan Kepulauan Raja Ampat sebagai pusat jantung "segitiga karang dunia" (Coral Triangle). Karakteristik fisik perairan Kepulauan Raja Ampat memungkinkan kawasan ini menjadi tempat tinggal yang nyaman bagi sejumlah biota perairan khususnya terumbu karang.Kedalaman perairan yang relatif dangkal, kejernihan air dan intensitas keterpaparan cahaya matahari yang cukup, menjadikan perairan Raja Ampat sebagai habitat yang baik untuk komunitas karang.

Selain itu, di Kabupaten Raja Ampat juga terdapat kawasan Suaka Alam Perairan Waigeo Barat.Perairan Kepulauan Waigeo sebelah Barat dan laut di sekitamya ditetapkan menjadi Kawasan Konservasi Perairan Nasional (KKPN) pada 3 September 2009 melalui Keputusan Menteri Kelautan 
dan Perikanan RI Nomor Kep.65/Men/2009.Keputusan tersebut menetapkan Perairan Kepulauan Waigeo sebelah Barat dan laut di sekitarnya sebagai Suaka Alam Perairan (SAP).Suaka Alam Perairan Kepulauan Waigeo sebelah Barat dan laut di sekitarnya di Provinsi Papua Barat terdiri atas Kepulauan Panjang dan laut di sekitarnya dengan luas sekitar 271.630 hektar. Secara geografis, kawasan Suaka Alam Perairan Kepulauan Waigeo Sebelah Barat dan laut laut di sekitarnya terletak

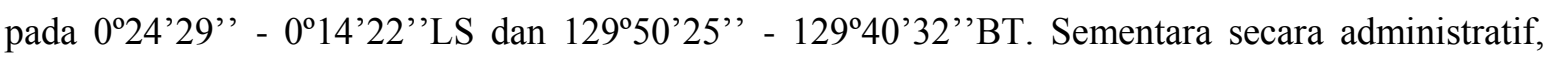
wilayah ini masuk ke dalam Distrik Waigeo Barat, Kabupaten Raja Ampat, Provinsi Papua Barat (Kepmen KP No.65/2009).

Sebagian besar penduduk (80\%) di Kabupaten Raja Ampat menggantungkan hidupnya pada sumberdaya hayati laut, utamanya sektor perikanan. Aktivitas pemanfaatan sumberdaya ikan di Kabupaten Raja Ampat hampir dipastikan akan bersentuhan langsung dengan keberadaan sumberdaya terumbu karang karena umumnya kegiatan pemanfaatan sumberdaya ikannya berada di wilayah perairan pantai yang merupakan habitat-habitat terumbu karang.

\section{Perumusan Masalah}

Terumbu karang merupakan ekosistem khas yang terdapat di daerah tropis.Terumbu karang di Indonesia bahkan dianggap sebagai pusat keanekaragaman hayati laut di wilayah segitiga terumbu karang dunia (the Coral Triangle).Kawasan ini membentang dari Laut Cina Selatan di utara sampai ke Laut Timor dan Laut Solomon di selatan, serta mencakup wilayah 6 (enam) Negara (Indonesia, Malaysia, Philippina, Timor Leste, Papua Nugini dan Kepulauan Solomon).Keragaman terumbu Indonesia terlihat dari struktur fisik (mulai dari terumbu tepi/fringing reef, atoll hingga terumbu penghalang/barrier reefs), maupun dalam hal struktur komunitas biologi yang mendukung keberadaan spesies karang (590 spesies karang batu), ikan terumbu (2.500 spesies), moluska, krustasea serta fauna dan flora yang berasosiasi di dalamnya.Dari sisi ekonomi, terumbu karang merupakan aset produktif yang penting bagi Negara dan bagi jutaan nelayan kecil yang bergantung pada keberadaan ekosistem ini.Kerusakan ekosistem terumbu karang berdampak kepada keberadaan biota yang bersimbiosis di dalamnya, diantaranya adalah ikan kerapu bara. Perubahan keadaan lingkungan berpengaruh terhadap kondisi biologi perikanan.Penelitian yang mengkaji biologi perikanan ikan dengan aspek lingkungan masih sangat terbatas, untuk itu penelitian tentang Kajian Biologi Perikanan Ikan Kerapu Bara di Kepulauan Raja Ampat ini dilakukan.

Tujuan dan Manfaat Penelitian

Penelitian ini bertujuan untuk:

1. Menganalisis nilai panjang pertama kali matang gonad (Lm), dan pertama kali tertangkap (Lc)

2. Menganalisis hubungan panjang berat (pola pertumbuhan) 
Manfaat Penelitian:

Penelitian ini memberi manfaat bagi:

1. Para peneliti sebagai bahan informasi dan pengetahuan terkait kondisi biologi perikanan ikan kerapu bara di Kepulaun Raja Ampat.

2. Pemerintah daerah setempat terkait upaya pengelolaan perikanan, terutama ikan kerapu bara.

\section{METODE PENELITIAN}

\section{Waktu dan Tempat Penelitian}

Penelitian dilaksanakan pada bulan Agustus tahun 2015 berlokasi di Distrik Waigeo Barat Kabupaten Raja Ampat Provinsi Papua Barat. Penelitian ini merupakan bagian dari penelitian yang didanai oleh Kementerian Kelautan dan Perikanan, cq. Direktorat Jenderal Perikanan Tangkap dalam kegiatan yang berjudul "Kajian Tingkat Pemanfaatan Sumberdaya Ikan Karang Terpilih Di WPNRI 715 dan $718 "$.

\section{Metode Pengumpulan Data}

Pengumpulan data dimaksudkan untuk memperoleh data baik primer maupun sekunder.Pengumpulan data dan informasi berasal dari dua sumber yaitu primer dan sekunder. Data primer adalah data hasil survei dan pengukuran secara langsung. Sumber kedua yaitu data dari lembaga atau institusi yang telah melakukan proses pengumpulan data lapangan dan mendokumentasikannya dalam bentuk laporan, buku, diagram, peta, foto, dan media penyimpanan lainnya.Teknik pengumpulan data, jenis dan sumber data, jumlah sampling, responden masingmasing domain dapat dilihat pada Tabel 1 .

Tabel 1. Teknik Pengumpulan Data, Jenis dan Sumber Data, Jumlah Sampling, Responden Masing-masing Domain

\begin{tabular}{llll}
\hline No. & Jenis Data Tiap Domain & \multicolumn{1}{c}{ Sumber Data } & Keterangan \\
\hline A. & Data Primer & & \\
\hline & Biologi perikanan & & $\begin{array}{l}\text { Metode rinci } \\
\text { dijelaskan tersendiri }\end{array}$ \\
\hline a. & Komposisi ukuran, Lc, Lm & & $\begin{array}{l}\text { Dilengkapai tabel } \\
\text { sheet data }\end{array}$ \\
\hline b. & Panjang dan berat & $\begin{array}{l}\text { pengukuran langsung, sampel } \\
\text { diambil dari TPI, pengumpul } \\
\text { ikan, konsentrasi nelayan, }\end{array}$ &
\end{tabular}




\begin{tabular}{|c|c|c|c|}
\hline & & $\begin{array}{l}\text { jumlah sampel } 30 \% \text { dari } \\
\text { populasi yang ada di tiap } \\
\text { lokasi. }\end{array}$ & \\
\hline c. & $\begin{array}{l}\text { Lc (panjang pertama kali } \\
\text { ditangkap) }\end{array}$ & $\begin{array}{l}\text { pengukuran langsung, sampel } \\
\text { diambil dari TPI, pengumpul } \\
\text { ikan,konsentrasi nelayan, } \\
\text { nelayan penangkap ikan }\end{array}$ & \\
\hline d. & $\begin{array}{l}\text { Lm (panjang pertama kali } \\
\text { matang gonad) }\end{array}$ & $\begin{array}{l}\text { Pembedahan, pengamatan } \\
\text { TKG ikan. Sampel diambil } \\
\text { dari TPI, pengumpul ikan, } \\
\text { konsentrasi nelayan, jumlah } \\
\text { sampel } 30 \% \text { dari populasi yang } \\
\text { ada di tiap lokasi }\end{array}$ & $\begin{array}{l}\text { Dilengkapi tabel } \\
\text { tingkat kematangan } \\
\text { gonad }\end{array}$ \\
\hline B. & Data Sekunder & & \\
\hline 1. & $\begin{array}{l}\text { Data produksi } 5 \text { tahun } \\
\text { terakhir jenis ikan kerapu } \\
\text { bara }\end{array}$ & $\begin{array}{l}\text { Dinas Kelautan dan Perikanan } \\
\text { Kabupaten, Provinsi }\end{array}$ & $\begin{array}{l}\text { Ground check di } \\
\text { lapangan }\end{array}$ \\
\hline 2. & $\begin{array}{l}\text { Kondisi terumbu karang, } \\
\text { lamun dan mangrove di dua } \\
\text { lokasi kajian }\end{array}$ & $\begin{array}{l}\text { Dinas Kelautan dan Perikanan } \\
\text { Kabupaten, Provinsi; Badan } \\
\text { Konservasi Sumberdaya Alam } \\
\text { (BKSDA); laporan penelitian } \\
\text { dari Coremap-LIPI; jurnal } \\
\text { hasil-hasil penelitian terkait. }\end{array}$ & $\begin{array}{l}\text { Ground check di } \\
\text { lapangan, penyelaman }\end{array}$ \\
\hline 3. & $\begin{array}{l}\text { Kondisi lingkungan perairan } \\
\text { lokasi kajian (suhu, pH, } \\
\text { salinitas, tingkat kecerahan, } \\
\text { arus) }\end{array}$ & $\begin{array}{l}\text { Dinas Kelautan dan Perikanan } \\
\text { Kabupaten, Provinsi; Badan } \\
\text { Konservasi Sumberdaya Alam } \\
\text { (BKSDA); laporan penelitian } \\
\text { dari Coremap-LIPI; jurnal } \\
\text { hasil-hasil penelitian terkait; } \\
\text { laporan BPLHD. }\end{array}$ & $\begin{array}{l}\text { Ground check di } \\
\text { lapangan, penyelaman }\end{array}$ \\
\hline 4. & $\begin{array}{l}\text { Time series data (minimal } 5 \\
\text { tahun) unit penangkapan ikan } \\
\text { (alat tangkap, kapal, nelayan) } \\
\text { karang selama lima tahun } \\
\text { terakhir }\end{array}$ & $\begin{array}{l}\text { Dinas Kelautan dan Perikanan } \\
\text { Kabupaten/Kota, Provinsi }\end{array}$ & $\begin{array}{l}\text { Ground check di } \\
\text { lapangan keberadaan } \\
\text { unit penangkapan ikan }\end{array}$ \\
\hline 5. & $\begin{array}{l}\text { Kondisi demografi lokasi } \\
\text { kajian }\end{array}$ & $\begin{array}{l}\text { Pemerintah Daerah Kabupaten, } \\
\text { Badan Pusat Statistik (BPS) }\end{array}$ & \\
\hline
\end{tabular}

Prosedur pengambilan contoh untuk analisis parameter biologi perikanan meliputi pengukuran panjang total $(\mathrm{cm})$, panjang cagak $(\mathrm{cm})$, panjang standar $(\mathrm{cm})$, bobot total $(\mathrm{gram})$, dan tingkat kematangan gonad berdasarkan klasifikasi Cassie 1956 dalam Effendie (2002).

Tabel2.Penentuan TKG secara morfologi (Cassie 1956 dalam Effendie 2002)

\begin{tabular}{|c|c|c|}
\hline TKG & Betina & Jantan \\
\hline I & $\begin{array}{l}\text { Ovari seperti benang, panjangnya sampai ke } \\
\text { depan rongga tubuh, serta permukaannya licin }\end{array}$ & $\begin{array}{l}\text { Testis seperti benang,warna jernih, dan } \\
\text { ujungnya terlihat di rongga tubuh }\end{array}$ \\
\hline II & $\begin{array}{l}\text { Ukuran ovari lebih besar. Warna ovari } \\
\text { kekuning-kuningan, dan telur belum terlihat } \\
\text { jelas }\end{array}$ & $\begin{array}{l}\text { Ukuran testis lebih besar pewarnaan seperti } \\
\text { susu }\end{array}$ \\
\hline III & $\begin{array}{l}\text { Ovari berwarna kuning dan secara morfologi } \\
\text { telur mulai terlihat }\end{array}$ & $\begin{array}{l}\text { Permukaan testis tampak bergerigi, warna } \\
\text { makin putih dan ukuran makin besar }\end{array}$ \\
\hline
\end{tabular}




\begin{tabular}{cll}
\hline IV & $\begin{array}{l}\text { Ovari makin besar, telur berwarna kuning, } \\
\text { mudah dipisahkan. Butir minyak tidak tampak, } \\
\text { mengisi } 1 / 2-2 / 3 \text { rongga perut }\end{array}$ & $\begin{array}{l}\text { Dalam keadaan diawet mudah putus, testis } \\
\text { semakin pejal }\end{array}$ \\
V & $\begin{array}{l}\text { Ovari berkerut, dinding tebal, butir telur sisa } \\
\text { terdapat didekat pelepasan }\end{array}$ & $\begin{array}{l}\text { Testis bagian belakang kempis dan dibagian } \\
\text { dekat pelepasan masih berisi }\end{array}$ \\
\hline
\end{tabular}

Pengambilan contoh ikan dapat dilakukan di pasar ikan/TPI, pengepul, dan nelayan penangkap ikan karang, selama satu bulan.Pengamatan dilakukan setiap hari, data yang diambil di pasar ikan/TPI, pengepul dan nelayan diambil secara acak sebesar 30\% dari populasi yang ada.Data fishing ground didapatkan melalui wawancara dengan nelayan ikan karang di sekitar titik pengamatan.

\section{Analisis Data}

Ukuran ikan pertama kali matang gonad (Lm)

Perdugaan panjang ikan pertama kali matang gonad (leght at first maturity) ditentukan melalui regresi logistik untuk mendapatkan kurva sigmoid. Regresi dilakukan antara proporsi kematangan (sumbu y) dengan ukuran panjang (sumbu $\mathrm{x}$ ), dengan persamaan:

$$
p x_{1}=\frac{e^{\left(b_{0}+b_{1} x_{1}\right.}}{\left(1+e^{\left(b_{0}+b_{1} x_{1}\right.}\right.}
$$

dimana:

$\mathrm{p}=$ peluang kematangan ikan dalam ukuran panjang atau interval panjang $\mathrm{x} 1$

b0 dan b1= konstanta

Prediksi panjang pertama kali matang gonad dihitung dengan formula:

$$
L_{50}=\frac{-b_{0}}{b_{1}}
$$

Ukuran ikan pertama kali ditangkap (Lc)

Pendugaan ukuran pertama kali ikan tertangkap dilakukan dengan membuat grafik hubungan antara panjang ikan (sumbu X) dengan jumlah ikan (sumbu Y) sehingga diperoleh kurva berbentuk sigmoid. Nilai legth at first capture yaitu panjang pada 50\% pertama kali tertangkap dihitung dengan persamaan sebagai berikut (Jones, 1976 dalam Sparre \& Venema, 1999) :

$$
\begin{gathered}
S_{\mathrm{L}}{ }^{\text {est }}=\frac{1}{1+\exp (\mathrm{S} 1-\mathrm{S} 2 * \mathrm{~L})} \\
\operatorname{Ln}\left[\frac{1}{S L}-1\right]=\mathrm{S}_{1}-\mathrm{S}_{2}{ }^{*} \mathrm{~L} \\
\mathrm{~L}_{50 \%}=\frac{S 1}{S 2}
\end{gathered}
$$

dimana:

SL $\quad=$ kurva logistik; $\mathrm{S}_{1}=\mathrm{a} ; \mathrm{S}_{2}=\mathrm{b}$

$\mathrm{S}_{1}$ dan $\mathrm{S}_{2} \quad=$ konstanta pada rumus kurva logistik 


\section{Hubungan panjang berat}

Model pertumbuhan ikan diasumsikan mengikuti pola hukum kubik dari dua parameter yang dijadikan analisis yaitu parameter panjang dan bobot. Analisis hubungan panjang bobot masing-masing spesies ikan digunakan rumus sebagai berikut (Effendie 2002):

$$
W=\alpha L^{\beta}
$$

$\mathrm{W}$ adalah bobot (gram), $\mathrm{L}$ adalah panjang total ikan $(\mathrm{mm}), \alpha$ dan $\beta$ adalah koefisien pertumbuhan bobot. Nilai $\alpha$ dan $\beta$ diduga dari bentuk linier persamaan di atas, yaitu:

$$
\log W=\log a+b \log L
$$

Parameter penduga a dan $b$ diperoleh dengan analisis regresi dengan log $W$ sebagai $y$ dan $\log L$ sebagai $x$, sehingga diperoleh persamaan regresi:

$$
y_{i}=\beta_{0}+\beta_{1} x_{i}+\varepsilon_{i}
$$

Sebagai model observasi dan $\hat{y}_{i}=b_{0}+b_{1} x_{i}$

Sebagai model dugaan.

Konstanta $b_{1}$ dan $b_{0}$ diduga dengan:

$$
b_{1}=\frac{\sum_{i=1}^{n} x_{i} y_{i}-\frac{1}{n} \sum_{i=1}^{n} x_{i} \sum_{i=1}^{n} y_{i}}{i=1 x_{i}-\frac{1}{n}{ }_{i=1}^{n} x_{i}^{2}}
$$

$$
\operatorname{danb}_{0}=\bar{y}-b_{1} \bar{x}
$$

Sedangkan $a$ dan $b$ diperoleh melalui hubungan $b=b_{1}$ dan $a=$ antilog $b_{0}$.

Hubungan panjang dan bobot dapat dilihat dari nilai konstanta $b$ (sebagai penduga tingkat kedekatan hubungan kedua parameter) yaitu dengan hipotesis:

1. $\mathrm{H}_{0}: \mathrm{b}=3$, dikatakan memiliki hubungan isometrik (pola pertumbuhan bobot sebanding pola pertumbuhan panjang)

2. $\mathrm{H}_{1}: \mathrm{b} \neq 3$, dikatakan memiliki hubungan allometrik (pola pertumbuhan bobot tidak sebanding pola pertumbuhan panjang)

Pola pertumbuhan allometrik ada dua macam yaitu allometrik positif (b>3) yang mengindikasikan bahwa pertumbuhan bobot lebih dominan dibandingkan dengan pertumbuhan panjang dan allometrik negatif $(b<3)$ yang berarti bahwa pertumbuhan

\begin{tabular}{|c|c|c|c|c|c|}
\hline \multirow[b]{2}{*}{ Sampel Jenis Ikan } & \multicolumn{3}{|c|}{ Panjang Tubuh Ikan (cm) } & \multirow[b]{2}{*}{ Berat $(g)$} & \multirow[b]{2}{*}{ TKG } \\
\hline & TL & FL & SL & & \\
\hline 1 & 28 & 24 & 22 & 221 & 1 \\
\hline 2 & 26,5 & 23 & 22,5 & 286 & 2 \\
\hline
\end{tabular}
panjang lebih dominan dibandingkan dengan pertumbuhan bobotnya.

\section{HASIL PENELITIAN}

\section{Nilai panjang pertama kali matang gonad (Lm), dan pertama kali tertangkap (Lc)}

Tabel 3. Hasil Pengukuran Parameter Biologi Ikan Kerapu Bara 


\begin{tabular}{|c|c|c|c|c|c|}
\hline \multirow[b]{2}{*}{ Sampel Jenis Ikan } & \multicolumn{3}{|c|}{ Panjang Tubuh Ikan (cm) } & \multirow[b]{2}{*}{ Berat $(g)$} & \multirow[b]{2}{*}{ TKG } \\
\hline & TL & FL & SL & & \\
\hline 3 & 27 & 24 & 21 & 267 & 1 \\
\hline 4 & 27 & 24 & 22 & 240 & 1 \\
\hline 5 & 25 & 23 & 21 & 215 & 2 \\
\hline 6 & 28 & 25 & 21 & 221 & 1 \\
\hline 7 & 22 & 20 & 19 & 147 & 1 \\
\hline 8 & 23,5 & - & 20 & 167 & 1 \\
\hline 9 & 40 & 36 & 32 & 707 & 1 \\
\hline 10 & 25 & - & 20 & 215 & 1 \\
\hline 11 & 27 & - & 22 & 275 & 1 \\
\hline 12 & 21,5 & - & 18 & 143 & 1 \\
\hline 13 & 32 & 28 & 24 & 362 & 2 \\
\hline 14 & 37 & 32 & 27 & 511 & 1 \\
\hline 15 & 36 & 31 & 27 & 487 & 1 \\
\hline 16 & 21 & 18,5 & 17 & 99 & 1 \\
\hline 17 & 24 & 21,5 & 19 & 154 & 1 \\
\hline 18 & 25,5 & & 21 & 235 & 1 \\
\hline 19 & 22,5 & - & 18,5 & 135 & 1 \\
\hline 20 & 32,5 & - & 28 & 195 & 2 \\
\hline 21 & 37,5 & - & 33,5 & 210 & 1 \\
\hline 22 & 27 & - & 23,5 & 147 & 1 \\
\hline 23 & 23,5 & - & 19 & 135 & 1 \\
\hline 24 & 29,5 & - & 25,5 & 215 & 1 \\
\hline 25 & 27 & 26 & 22 & 212 & 1 \\
\hline 26 & 32 & 31 & 26 & 396 & 1 \\
\hline 27 & 26 & 25 & 21 & 171 & 1 \\
\hline 28 & 28,5 & 27 & 24 & 257 & 2 \\
\hline 29 & 28 & 27 & 23,5 & 247 & 3 \\
\hline 30 & 26,5 & 25.5 & 21,5 & 221 & 1 \\
\hline 31 & 31,5 & 30.5 & 28 & 390 & 1 \\
\hline 32 & 28 & 25 & 22 & 235 & 1 \\
\hline 33 & 21 & 19 & 17 & 113 & 1 \\
\hline
\end{tabular}

Sumber: Data primer, diolah, 2015.

Keterangan: $\mathrm{TL}=$ total length (panjang total); $\mathrm{FL}=$ fork length (panjang cagak); $\mathrm{SL}=$ standart length

Terlihat dari data bahwa rata-rata ikan yang tertangkap berukuran sangat kecil dan belum dewasa.Berdasarkan data hasil pengukuran parameter biologi ikan di wilayah Kepulauan Raja Ampat dapat terindentifikasi sebagai berikut; untuk jenis ikan kerapu bara panjangnya berkisar 21$40 \mathrm{~cm}$ dengan nilai rata-rata $27,78 \mathrm{~cm}$, sementara frekuensi beratnya berkisar 99-707 gram dengan nilai rata-rata 249,42 gram. Berdasakan Tabel 3 terlihat bahwa ikan yang pertama kali tertangkap sebanyak $90 \%$ belum matang gonad (TKG I dan TKG II). 
Berdasarkan hasil perhitungan nilai Lm dan Lc Ikan Kerapu Bara di perairan Waigeo Barat didapatkan nilai $\mathrm{Lc} 25,37 \mathrm{~cm}$, dan nilai $\mathrm{Lm} 29,91 \mathrm{~cm}$ yang berarti ikan ini merupakan ikan yang belum layak tangkap $(\mathrm{Lc}<\mathrm{Lm})$.

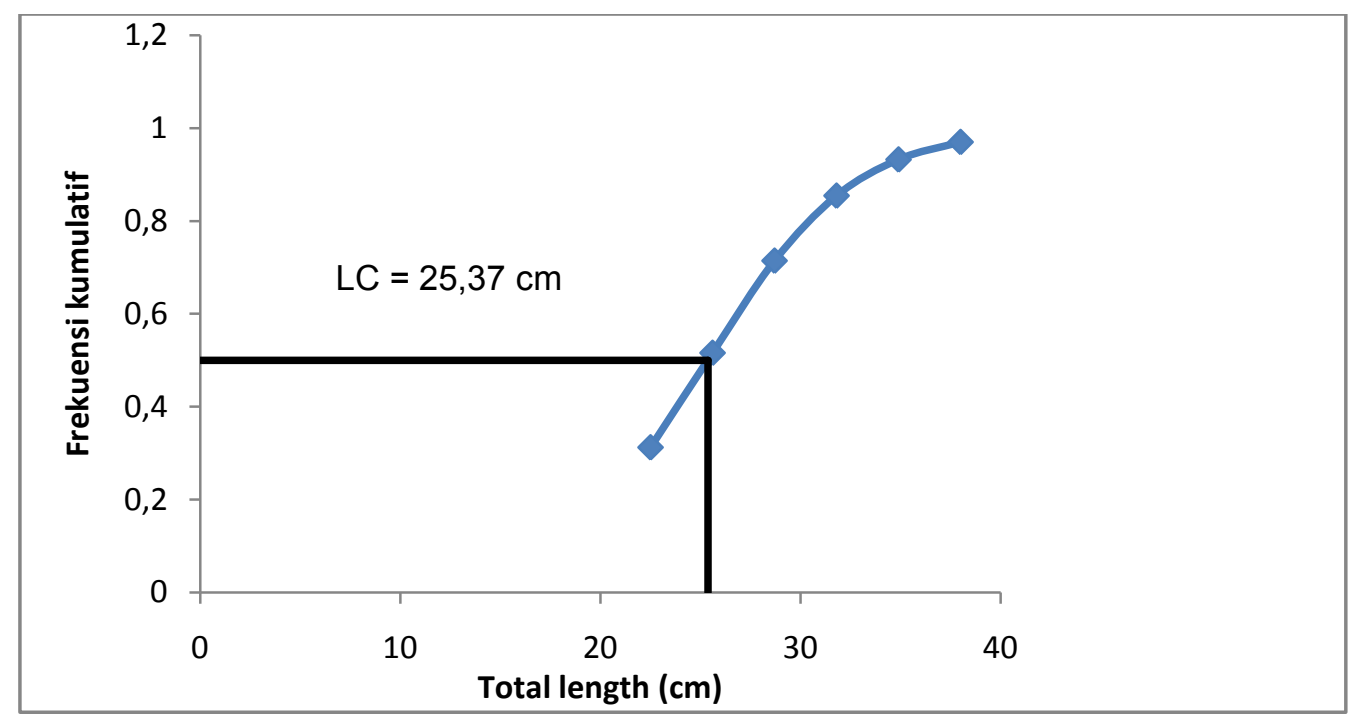

Gambar 1. Grafik Lc Ikan Kerapu Bara

\section{Hubungan panjang berat (pola pertumbuhan)}

Berdasarkan hasil perhitungan hubungan panjang berat, diperoleh nilai b sebesar 2,219 atau nilai $b<3$ yang dengan kata lain pertumbuhan panjang ikan kerapu bara yang tertangkap di Waigeo Barat bersifat allometrik negatif (pertambahan panjang ikan lebih cepat dari pada pertambahan beratnya). Merta (1993), menyatakan keadaan lingkungan yang sering berubah menyebabkan kondisi ikan juga berubah, hal ini yang menyebabkan hubungan panjang berat akan sedikit menyimpang dari hukum kubik $(b \neq 3)$ (Gambar 2).

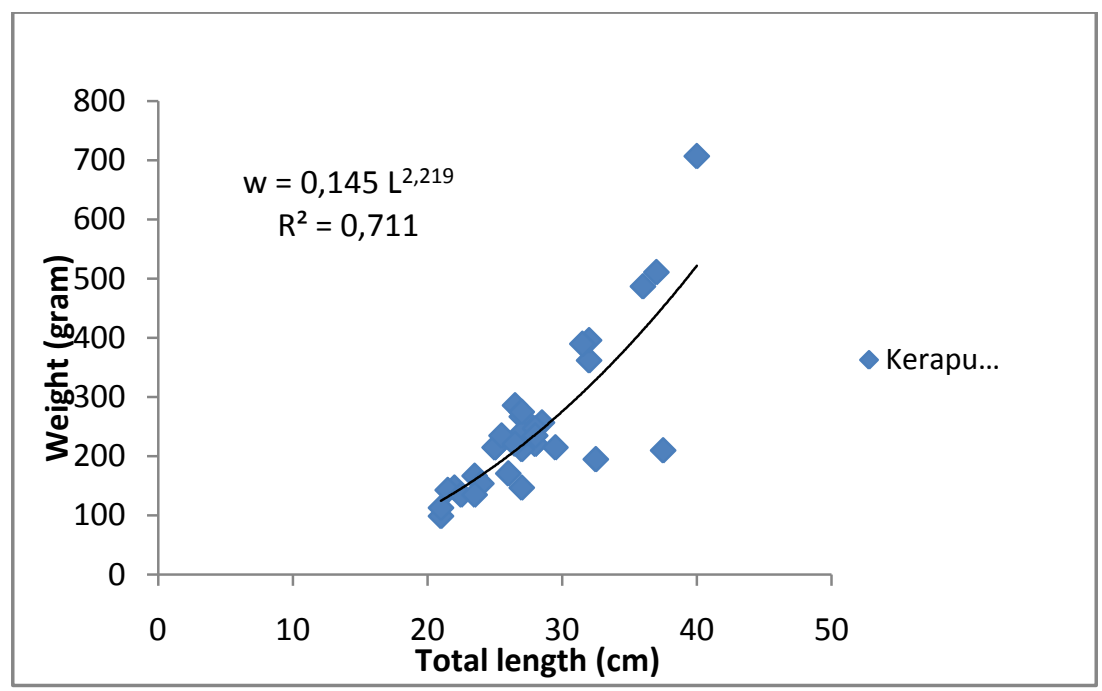

Gambar 2.Grafik Hubungan Panjang Berat Ikan Kerapu Bara 


\section{PEMBAHASAN}

Kondisi perikanan kerapu bara di perairan Kabupaten Raja Ampat tepatnya di Waigeo Barat menunjukkan bahwa ikan yang ditangkap belum layak tangkap dari sisi tingkat kematangan gonad (TKG) dan ukuran bobot ikan. Ikan pertama kali matang gonad biasanya dipengaruhi oleh panjang dan berat tubuh ikan dan juga faktor lingkungan.Menurut Habibi et.al (2011) ikan kerapa bara/merah merupakan salah satu spesies kelompok kerapu sunu, dengan nama umum Leopard Coral Grouper, dengan nama daerah sunu asli/merah. Panjang layak tangkap berkisar 21-60 cm. Berdasarkan data hasil tangkapan menunjukkan bahwa ukuran panjang ikan kerapu bara yang ditangkap masih dalam batas selang ukuran panjang yang layak ditangkap. Namun demikian tidak dengan kondisi TKG nya. Panjang ikan pada saat ditangkap seharusnya melebihi panjang saat matang gonad yaitu lebih dari 29,91 cm. Hal ini menggambarkan bahwa ikan kerapu bara yang terdapat di perairan Waigeo Barat masih berukuran kecil (TKG didominasi TKG I dan II).

Kondisi lingkungan di lokasi penelitian terdiri dari ekosistem terumbu karang, lamun dan mangrove. Kondisi ekosistem karang yang masih bagus akan menjamin kelangsungan hidup, pertumbuhan dan ketersediaan makanan bagi ikan kerapu. Karang hidup yang kondisinya masih bagus akan sesuai untuk tempat persembunyian (shelter) bagi ikan kerapu, ikan-ikan kecil dan krustasea. Ikan-ikan kecil dan krustasea tersebut merupakan sumber makanan utama bagi ikan kerapu. Berdasarkan hasil pembedahan terhadap isi perut ikan kerapu, diperoleh data bahwa ikan kerapu merah merupakan jenis ikan Omnivora, dengan makanan utamanya adalah berasal dari kelas Dinophyceae (Dinophysis) dengan persentase sebesar 19\% dan makanan tambahannya adalah kelas Bacillariophyceae (Rhizosolenia) sebesar 6\% serta Copepoda sebesar 10\%. Ikan kerapu bara juga bersimbiosis dengan ikan karang lainnya. Hal ini ditunjukkan dengan kelimpahan ikan terbanyak ditemukan di Wayag sebesar 25.280 individu/ha.

Kondisi hasil tangkapan yang berukuran kecil, diduga sebelumnya dilakukan penangkapan tidak hanya oleh nelayan lokal namun juga nelayan luar.Usaha penangkapan dilakukan baik perorangan maupun perusahaaan yang menggunakan berbagai jenis alat tangkap seperti pancing (hand line), huhate (pole and line), jaring insang (gill net), bagan (lift net), mini purse seine, dan trammel net.Di Raja Ampat ditemukan 14 jenis alat tangkap.Alat tangkap yang paling dominan dan tersebar hampir di setiap distrik adalah pancing dasar dan pancing tonda.Berdasarkan alat tangkap yang digunakan, teknologi penangkapan nelayan Raja Ampat masih sederhana.

Pada saat pengamatan di lapangan ditemukan alat tangkap yang sangat tradisional, sehingga diduga yang melakukan penangkapan dalam jumlah besar bukan nelayan tradisional. Berdasarkan wawancara dengan nelayan dan pengamatan di lapangan, menunjukkan bahwa jenis alat tangkap yang digunakan untuk menangkap ikan karang di Kabupaten Raja Ampat adalah pancing (dasar), pancing tonda, tombak dan panah. Keempat alat tangkap ini digunakan oleh nelayan sekitar untuk 
menangkap ikan dengan menyesuaikan musim ikan yang ada.Berdasarkan alat tangkap yang digunakan, teknologi penangkapan nelayan Raja Ampat masih sederhana (Gambar 3).

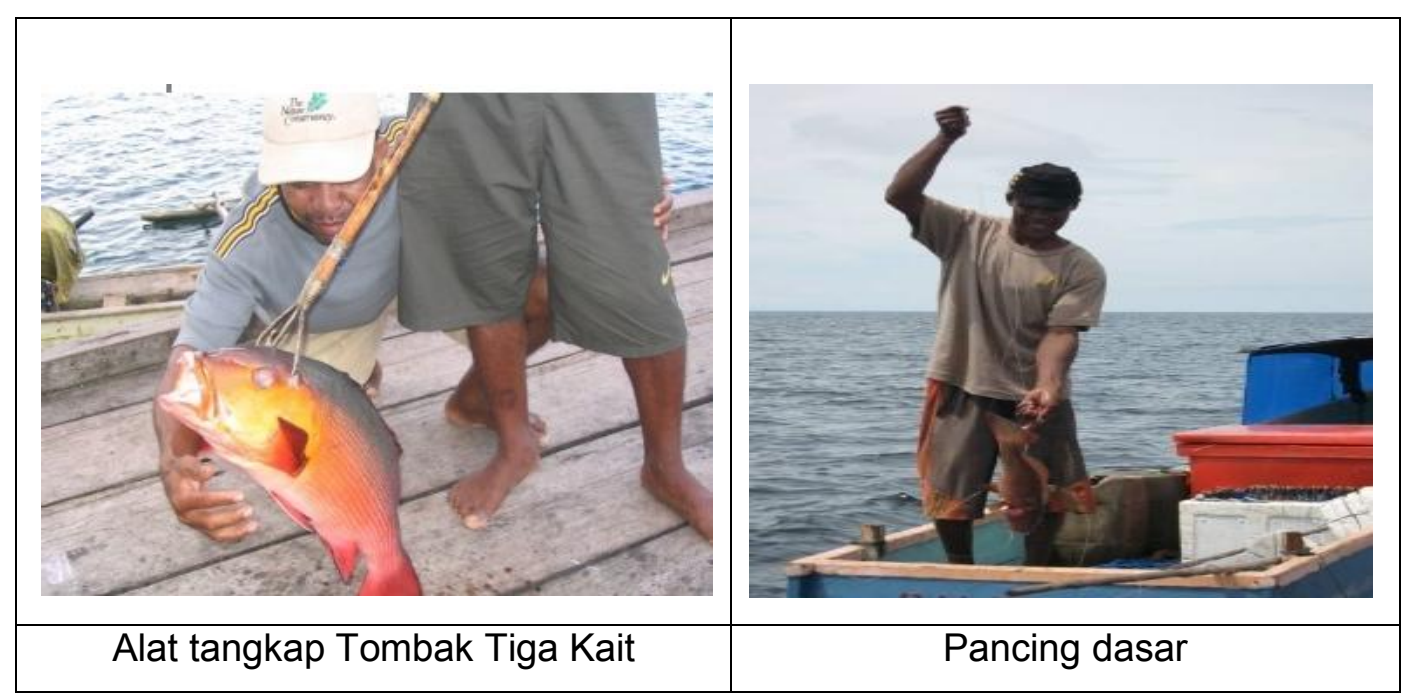

Gambar 3 Alat Tangkap yang Digunakan di Kabupaten Raja Ampat

Pada Gambar 3 menunjukkan bahwa alat tangkap yang digunakan masih sangat tradisional, sangat selektif dan ramah lingkungan. Pancing dasar yang digunakan dikelompokkan ke dalam hand line (pancing ulur). Pancing ulur merupakan alat tangkap yang sederhana baik secara fisik maupun cara pengoperasiannya. Secara umum alat penangkap ikan ini terdiri atas tali pancing, penggulung tali, pemberat, swivel, mata pancing (hook), dan menggunakan umpan dalam pengoperasiannya

Alat tangkap pancing ulur tersebar luas di Indonesia dan merupakan alat tangkap yang sering digunakan nelayan tradisional. Pancing ulur tidak banyak menggunakan alat bantu seperti alat tangkap pukat ikan dan pukat cincin, pengoperasiannya yang sederhana, merupakan alat tangkap aktif, ramah lingkungan dan dapat dioperasikan di berbagai jenis perairan. Pancing ulur juga relatif mudah dibuat dan umumnya para nelayan dengan skala kecil membuatnya sendiri.

Armada penangkapan yang digunakan adalah perahu tanpa motor, perahu motor katinting dan perahu motor tempel, dengan lama operasi 1 hari /trip (one day fishing). Daerah penangkapan sangat terbatas, tidak jauh dari daerah tempat tinggal (0-2 mil). Kegiatan penangkapan dilakukan 34 hari dalam seminggu, dengan lama waktu kerja antara 4-12 jam per hari.

Adapun para nelayan dari luar, yaitu dari Sorong dan Sulawesi, menggunakan kapal motor dengan kapasitas yang besar. Perahu tanpa motor yang digunakan nelayan lokal pada umumnya adalah perahu yang menggunakan semang dengan ukuran 3-7 m. Armada ini merupakan pilihan utama masyarakat Kabupaten Raja Ampat karena tidak membutuhkan bahan bakar minyak. Adapun perahu yang menggunakan motor tempel ukurannya lebih panjang dari $7 \mathrm{~m}$. Kapal motor dengan ukuran di atas 10 GT banyak digunakan oleh nelayan dari luar Raja Ampat. 
Ancaman-ancaman terhadap kelestarian sumberdaya laut di Raja Ampat diantaranya adalah adanya nelayan luar dan penggunaan alat tangkap yang merusak. Berdasarkan hasil penelitian yang dilakukan Direktorat Sumber Daya Ikan (2014), menunjukkan bahwa sebesar 77\% responden menyatakan terjadinya penurunan hasil tangkapan di Distrik Waigeo Barat, 96\% menggunakan bahan peledak, $85 \%$ penggunaan sianida dan 38\% nelayan luar.Penangkapan ikan menggunakan bahan peledak sangat merugikan di lokasi yang berekosistem terumbu karang. Kerugian yang ditanggung masyarakat akibat penggunaan bahan peledak ini diperkirakan sebesar USD 306.800 per $\mathrm{km}^{2}$ terumbu karang dalam jangka waktu 20 tahun (Pet-Soede et al. 1999dalam Direktorat Sumberdaya Ikan, 2014). Meskipun beberapa penduduk lokal ikut terlibat menggunakan bahan peledak dan sianida, nelayan luar yang berkolusi dengan figur penguasa diyakini sebagai pelaku utama dari praktek-praktek ini. Nelayan luar juga membuat pengaturan bisnis dengan masyarakat lokal dengan cara menyediakan bahan-bahan alat tangkap yang merusak dan membuat perjanjian pembelian (Direktorat Sumberdaya Ikan, 2014). Hal ini menunjukkan bahwa tiga ancaman terbesar terhadap sumberdaya laut di Raja Ampat itu saling terkait dan berhubungan dengan nelayan luar.

\section{KESIMPULAN DAN SARAN}

Kesimpulan

Berdasarkan hasil kajian dapat disimpulkan bahwa:

1. Ikan Kerapu Bara di perairan Waigeo Barat memiliki nilai $\mathrm{Lm} 29,91 \mathrm{~cm}$ dan Lc 25,37 cm, menunjukkan bahwa ikan yang tertangkap belum layak tangkap $(\mathrm{Lc}<\mathrm{Lm})$.

2. Berdasarkan hasil perhitungan hubungan panjang berat, diperoleh nilai $b$ sebesar 2,219 atau nilai $b<3$ yang dengan kata lain pertumbuhan panjang ikan kerapu bara yang tertangkap di Waigeo Barat bersifat allometrik negatif (pertambahan panjang ikan lebih cepat dari pada pertambahan beratnya).Pola pertumbuhan ikan kerapu bara mengikuti persamaan $\mathrm{W}=$ $0,145 \mathrm{~L}^{2,219}$

Saran

Disarankan untuk melakukan penelitian dalam tiga musim yang berbeda, yaitu musim barat, musim peralihan dan musim paceklik. 


\section{DAFTAR PUSTAKA}

Direktorat Sumber Daya Ikan. 2014. Preliminery Study Penilaian Indikator EAFM di Lokasi Coremap-CTI BW-TA. Direktorat Jenderal Perikanan Tangkap, Kementerian Kelautan dan Perikanan. Jakarta.

Effendie, M.I. 2002. Biologi Perikanan. Yayasan Pustaka Nusatama, edisi Kedua, Yogyakarta : 163 hlm.

Habibi A., Sugiyanta, Candika Yusuf. 2011. Perikanan Kerapu dan Kakap.Panduan Lengkap dan Penanganan. Seri Panduan Perikanan Skala Kecil. WWF-Indonesia.

Sparre,P and Venema, S.C.1999. Introduction to Tropical Fish Stock Assesment.Part 1.Manual 1. FAO Fisheries Technical Paper (Revised edition). 